\title{
Association between the ELAVL1 gene single nucleotide polymorphisms and the Genetic Susceptibility to cervical cancer by high resolution melting in a Tunisian population
}

Najet Boudhiba ( $\square$ najetboudhiba@gmail.com )

Universite de Monastir Institut Superieur de Biotechnologie de Monastir https://orcid.org/0000-00022369-5031

\section{Sana Sfar}

Universite de Monastir Faculte de Pharmacie de Monastir

\section{Ahlem Helaoui}

Universite de Monastir Institut Superieur de Biotechnologie de Monastir

\section{Marcin Hołysz}

Poznan University of Medical Sciences 2nd Faculty of Medicine: Uniwersytet Medyczny im Karola Marcinkowskiego w Poznaniu Wydzial Medyczny

\section{Ewa Iwańczyk-Skalska}

Poznan University of Medical Sciences 2nd Faculty of Medicine: Uniwersytet Medyczny im Karola Marcinkowskiego w Poznaniu Wydzial Medyczny

\section{Haifa Bouchahda}

University of Monastir: Universite de Monastir

\section{Paweł piotr Jagodziński}

Poznan University of Medical Sciences 2nd Faculty of Medicine: Uniwersytet Medyczny im Karola Marcinkowskiego w Poznaniu Wydzial Medyczny

\section{Abderraouf KENANI}

Universite de Monastir Faculte de Medecine de Monastir

\section{Research Article}

Keywords: cervical cancer, HuR, polymorphism, RNA-binding protein, HRM

Posted Date: February 11th, 2022

DOI: https://doi.org/10.21203/rs.3.rs-1324538/v1

License: (c) (i) This work is licensed under a Creative Commons Attribution 4.0 International License. Read Full License 
Page $2 / 23$ 


\section{Abstract}

Background: Human papillomavirus infection is the major cause of cervical cancer, but only few cases develop into cancer. Although, HuR (ELAVL1) gene has been implicated in the oncogenesis of certain cancers. However, the correlation between the ELAVL1 gene and the risk of cervical cancer in Tunisian women remains unclear. Therefore, this study investigated the effect of ELAVL1 gene polymorphisms (SNPs) in cervical cancer development.

Method: ELAVL1 gene SNPs: ELAVL1 rs12983784 T>C, ELAVL1 rs14394 T>C, ELAVL1 rs74369359 G>T, ELAVL1 rs35986520 G>A, ELAVL1 rs10402477 C>T, ELAVL1 rs12985234 A>G, ELAVL1 rs2042920 T>G, were genotyped by High resolution melting (HRM). SHEsis online software was used to perform linkage disequilibrium (LD) and haplotype analyses.

Results: Comparing the cervical cancer patients with healthy control participants, the TC genotype of rs 12983784 SNP $(\mathrm{P}=0.017, \mathrm{OR}=2.78,95 \% \mathrm{Cl}=1.2 \sim 6.45)$, the $\mathrm{GT}$ genotype of the $r$ 74369359 SNP $(\mathrm{P}=0.004, \mathrm{OR}=9.4,95 \% \mathrm{Cl}=1.73 \sim 16.96)$ and the $\mathrm{CT}$ genotype of the rs10402477SNP $(\mathrm{P}=0.002, \mathrm{OR}=$ $5.89,95 \% \mathrm{Cl}=1.89 \sim 18.36)$ were associated with increased cervical cancer risk. TT genotype of rs 12983784 SNP ( $P=0.005), G G$ genotype of the rs74369359 SNP $(P=0.000)$ and CC genotype of the rs10402477 SNP $(P=0.000)$ were considered as protective factors against cervical cancer in the Tunisian population.

The haplotype analysis of the 7 SNPs of ELAVL1 gene suggested that "C C G G C A G" (P=0.02), "T T G G T A T" ( $P=0.01)$ and "T T T G C A T" $(P=0.002)$ were a significant risk factor for cervical cancer. However, "TCGACAT" $(P=0.04)$ and "TTGGCAT" $(P=0.04)$ participated in the decrease of cervical cancer disease.

The frequency of ELAVL1 haplotype rs10402477-rs2042920 TT was significantly higher in the cases group than in the control group $(P=0.0001)$.Thus, this genotype increases cervical cancer risk among Tunisian women.

Conclusion: The results of our study indicated that genetic variants in the ELAVL1 gene might be associated with susceptibility to cervical cancer in the Tunisian population.

\section{Introduction}

Cervical cancer is the fourth most frequent type of malignancy in women worldwide, and second most predominant cause of cancer-associated mortality among women in developing countries in 2018; with an estimated 604,237 women diagnosed with cervical cancer globally, representing $6.5 \%$ of all female cancers. Cervical cancer is the most common cancer among women in 36 low-and middle-income countries (Sung, Ferlay et al. 2021).

In addition, cervical cancer caused by HPV is the fifth leading cause of cancer deaths in women in Tunisia, causing at least 199 deaths in 2018 among the 4.5 million Tunisian women aged 15 years and 
older who are at risk for the disease (Wanke, Devanna et al. 2018).

Epidemiological studies have proved that infections by certain types of Human papillomavirus (HPV) are closely linked to cervical cancer development. Those studies considered HPV as the major risk factor for the disease with more than $95 \%$ of patients with cervical cancer testing positive for HPV genital infection (Walboomers, Jacobs et al. 1999, Spence, Franco et al. 2005). In addition, environmental risk factors such as smoking habit (Sugawara, Tsuji et al. 2019), occupational history (Charbotel, Massardier-Pilonchery et al. 2013), the oral contraceptive use (Asthana, Busa et al. 2020), diet (Medina-Contreras, Luvián-Morales et al. 2020) and sexual behavior contribute to the onset and progression of cervical cancer. Genetic factors intensify cervical cancer development as well (Bahrami, Hasanzadeh et al. 2018) (Tang, Chen et al. 2019); (Chen, Yang et al. 2020).

Actually, not all the cases of HPV infections develop into cancer, which proves that genetic factors can contribute to the occurrence of cervical cancer. Taking into account the importance of the regulation of many growth factors, proto-oncogenic factors and cytokines, on the development of a cell cancer, by differential RNA stability, many events must occur precisely to generate the protein product accurately and efficiently.

An estimate ranging from $8-16 \%$ of several human protein-coding genes has a $3^{\prime} U T R$ adenylate and uridylate (AU)-rich elements (AREs) sequence. Those AREs are defined by their ability to promote rapid deadenylation dependent mRNA decay, mRNA stabilization or translational silencing (Rothamel, Arcos et al. 2021). The ARE may therefore be considered as a crucial regulator of mRNA function at several steps during the lifetime of a transcript.

The ARE binding protein HuR (Hu antigen R; ELAV Like1) which is a ubiquitously expressed member of the ELAV Like family of RNA binding proteins, stabilizes some ARE-containing mRNAs in cells. In cell cancer, HuR promotes cancer-related gene expression (Pauzas, Gyvyte et al. 2020, Yang, Yu et al. 2021).

Several studies have shown that HuR levels are upregulated in tumor tissues. Although HuR and its associated RNA-binding factors have been investigated in different types of cancer, it is still unclear how this phenomenon occurs in cervical cancer (Lim, Kim et al. 2007, Wang, Guo et al. 2013, Tifaoui, Maudelonde et al. 2018, Xue, Li et al. 2019, Filippova and Nabors 2020, Pauzas, Gyvyte et al. 2020).

In the present study, we aim to investigate genetic polymorphisms in the ELAVL1 gene with cervical cancer risk among Tunisian women.

Research in this field is extremely important to identify new biomarkers and targets that can be used in the future therapeutic approaches of this disease.

\section{Materials And Methods}

\section{Study population}


A total of 171 female participants were recruited from the Department of Gynecology and Obstetrics at Tahar Sfar University Hospital, Mahdia, Tunisia.

All participants (71 patients with pathologically Cervical cancer were classified as the study group and 100 women served as a Healthy control group) were enrolled and their peripheral blood samples were collected.

The patients and control subjects were from the same geographical area and belonged to the same ethnic group. Each participant was interviewed and a short questionnaire about social and demographic features such as age, occupational exposure history, family cancer history, pregnancy and delivery history, sexual behavior and the use of oral contraceptives was carried out to investigate the increased risk of cervical cancer. Approval of the Ethical Committee (CER-SVS/ISBM 007/2021) and written informed consent from all women in the study were obtained.

The case group this group included patients with confirmed a cervical cancer pathology attending their reproductive healthcare consulting in the obstetrics and gynecology department. Their ages ranged from18 to 76 years.

The healthy control group: this group included patients with no individual history of cancer. Participants in this group were randomly selected and they were matched with those in the study group by age and geographic location.

\section{DNA extraction from peripheral blood lymphocytes}

Peripheral venous blood was collected from each participant using an EDTA anticoagulated tube. A salting out method was performed to extract genomic DNA from blood samples.

$5 \mathrm{~mL}$ of each sample was placed into glass tubes. Then $5 \mathrm{~mL}$ of sterilized water was added. The tubes were centrifuged for $15 \mathrm{~min}$ at $3000 \mathrm{rpm}$. The supernatant was discarded, $20 \mu \mathrm{l}$ Tris $\mathrm{HCL}(1 \mathrm{M}), 20 \mu \mathrm{l}$ $\mathrm{NaCl}(5 \mathrm{M}), 40 \mu \mathrm{l} \operatorname{EDTA}(0,5 \mathrm{M}), 20 \mu \mathrm{l} \mathrm{PK}$ and $120 \mu \mathrm{LSDS}(10 \%)$ were added to the pellets. The samples were vortexed for $1 \mathrm{~min}$. These tubes were incubated in a bain marie at $55 \otimes \mathrm{C}$ for $2 \mathrm{H}$. Than we added $666 \mu \mathrm{l} \mathrm{NaCl}$ to each tube, and finally placed them in the refrigerator at $+4 \otimes \mathrm{C}$ for $15 \mathrm{~min}$. The tubes were centrifuged for $15 \mathrm{~min}$ at $3000 \mathrm{rpm}$. The supernatant was transferred quickly to fresh microfuge tubes and DNA was precipitated by the addition of $1.5 \mathrm{ml}$ of ethanol. DNA precipitate was retrieved using a heat-sealed, thin-end glass pipette, washed twice with $0.5 \mathrm{~mL}$ of $70 \%$ ethanol, and finally dissolved in sterilized water. The precipitate was completely dissolved and stored at $-80^{\circ} \mathrm{C}$.

Extracted DNA was quantified by using a Thermo NanoDrop Nd-1000 Spectrophotometer.

\section{Genetic polymorphism Testing}


For specific SNP loci, a High Resolution Melting curve analysis (HRM) using HOT FIREPol EvaGreen (Solis BioDyne, Tartu, Estonia) with a LightCycler 480 system (Roche Diagnostics, Mannheim, Germany) was performed for the detection and analyses of polymorphisms. Analysis was performed using Applied Biosystems High Resolution Melt Software.

HRM analysis was performed on double-stranded (ds) DNA samples. The DNA was amplified using a real-time platform prior to the HRM melt phase. The HRM process is a slow denaturation of the ds DNA from $50-95^{\circ} \mathrm{C}$ in conjunction with an intercalating of a fluorescent dye. The fluorescence level drops when the two strands 'melt' apart. The shape of the curve is dependent upon the characteristics of the ds DNA, which relate to whether it is homozygous wild type, homozygous mutant or heterozygous wild type and mutant. As the HRM is monitored in real-time, this curve gives a real time picture of the characteristics of the DNA being tested.

\section{Statistical analysis}

The association between ELAVL1 gene polymorphisms and genetic susceptibility to cervical cancer was examined by the P-values, odds ratio (OR) and $95 \%$ confidence intervals (Cl).

All the data were analyses performed with SPSS software 22.0. The SHEsis online software (http://analysis.bio-x.cn) was used to analyze linkage disequilibrium (LD) and to calculate haplotype frequencies for each SNP locus in the case group and control group. $\mathrm{P}<0.05$ was considered to indicate a statistically significant difference.

\section{Results}

\section{Characteristics of study subjects:}

In this study, the distribution of clinical and demographic characteristics of the healthy women and patients are presented in Table 2. No significant difference was observed in the frequency of distribution of age $(P=0.13)$, occupational status $(P=0.4)$, marital status $(P=0.14)$, childbirth $(P=0.08)$ and the use of the oral contraceptives $(P=0.81)$ in patients with cervical cancer and in healthy controls. No correlation was found between those characteristics and the risk of cervical cancer in the observed Tunisian population.

In contrast, the frequency of healthy women in high school was higher compared with that of patients ( $51 \%$ vs. $36.6 \%, P=0.01$ ), which proves that educated women are more health conscious than those with a low educational level (Fang, Lee et al. 2019, Kashyap, Krishnan et al. 2019) (27).

Study subjects who had menarche after 16 years of age were at a significantly higher risk of cervical cancer with a higher frequency in the case group than in control subjects $(9.9 \% \mathrm{vs.} 8 \% ; P=0.04, \mathrm{OR}=$ 
$1.89,95 \% \mathrm{Cl}=1.03 \sim 3.47)$. Women having menarche before the age of 16 presented an elevated frequency in the control group ( $92 \%$ vs. $91.9 \% ; \mathrm{P}=0.04)$

The risk for cervical cancer increases when women reach menopause. In fact, women who did not reach menopause had a higher frequency in controls than in cases ( $66 \%$ vs. $54.9 \% ; P=0.04)$. Menopausal women were more frequent among patients than among controls $(45.1 \% \mathrm{vs.} 34 \%$; $P=0.04 ; \mathrm{OR}=1.8,95 \%$ $\mathrm{Cl}=0.98 \sim 3.3)$

We found that women who experienced more than five pregnancies had a significantly higher frequency in the case group than in healthy control group $(25.2 \%$ vs. $22 \% ; \mathrm{P}=0.02 ; \mathrm{OR}=2.4,95 \% \mathrm{Cl}$ $=1.1 \sim 5.51)$. Women who had fewer than two pregnancies had a higher frequency in the control group than in patients ( $36 \%$ vs. $23.9 \% ; P=0.04)$, which proves that a high number of pregnancies is a risk factor for cervical cancer.

Moreover, the frequency of women with a family history of different types of cancers was found to be higher in among patient group than the healthy control group ( $57.7 \%$ vs. $39 \% ; P=0.012 ; \mathrm{OR}=2.18,95 \% \mathrm{Cl}$ $=1.18 \sim 4.02$ ). Contrarily women without a family history of cancer had a significantly higher frequency in controls than in the case group ( $61 \%$ vs. $42.3 \%$; $P=0.012)$. This confirms that a family history of cancer $i$ is a significant risk factor for developing cervical cancer.

\section{Genotype frequencies of Single Nucleotide Polymorphisms of ELAVL1 gene in Patients with cervical cancer and healthy control women}

The distribution of genotype frequencies of the seven SNPs (rs12983784, rs14394, rs74369359, rs35986520, rs10402477, rs12985234, rs2042920) are summarized in Table 3.

In the present study, we compared genotypic frequencies of the selected SNPs between controls and patients, and we found that the distribution of genotypes was different.

Genotypic frequencies of ELAVL1 gene SNPs (rs14394, rs35986520, rs1298524 and rs2042920) were not significantly different between the two study groups of healthy women and patients with cervical cancer.

The observed genotypic frequency TC of rs12983784 SNP in patients was significantly higher than that in controls $(\mathrm{P}=0.017, \mathrm{OR}=2.78,95 \% \mathrm{Cl}=1.2 \sim 6.45)$ which suggests that $\mathrm{TC}$ genotype increased cervical cancer risk. In contrast, TT genotypic frequency was significantly higher in the control group than in patients $(P=0.005)$ which indicates a protective effect of this genotype.

GT genotype of the rs74369359 SNP showed a statistically significant difference among patients $(P=0.004, O R=9.4,95 \% \mathrm{Cl}=1.73 \sim 16.96)$, but the $\mathrm{GG}$ genotype is statistically higher in the control group 
$(P=0.000)$. While GT genotype was found to be a risk factor for cervical cancer, $G G$ genotype was a protective factor.

The same result was obtained with the CT genotype of the SNPrs10402477that was associated with an increased risk of the disease by a higher manifestation in the patient group $(P=0.002, O R=5.89,95 \% \mathrm{Cl}$ $=1.89 \sim 18.36)$. $C C$ genotype frequency was significantly higher in the control group $(P=0.000)$ and it was considered as a protective factor against cervical cancer in the Tunisian population.

Collectively, out of all seven SNPs evaluated in ELAVL1 gene, statistics demonstrated that only ELAVL1 gene SNPs (rs12983784, rs74369359 and rs10402477) were associated with an increased risk of cervical cancer in Tunisian women.

\section{Association between SNPs, haplotypes and cervical cancer risk}

Single-locus association analyses of allelic frequency in each group (case and controls) for the ELAVL1 SNPs are presented in Table 4, There were no significant differences of allele frequencies between overall cervical cancer patients and controls at any of those analyzed SNPs $(P>0.05)$ except for rs 10402477 and rs12983784, where there was a significant difference between patients and controls in allele frequencies of $r$ 10402477 SNP $(P=0.0001)$ and the rs12983784 SNP $(P=0.011)$. For the rs 10402477 SNP, the frequency of the allele " $T$ " was significantly higher in cases than that in controls $(0.134 \%$ vs. $0.025 \%)$ contrary to the allele " $C$ " which had a higher frequency in controls $(0.975 \%$ vs. $0.866 \%)$, thus suggesting that the " $T$ " allele was a risk factor for cervical cancer development and that the " $\mathrm{C}$ " allele was a protective allele against the risk of cervical cancer. Furthermore, the frequency of the allele " $\mathrm{C}$ " of the rs 12983784 SNP was significantly higher in cases than in controls $(0.169 \%$ vs. $0.080 \%)$ so we suggested that this allele was a risk factor. However, the "T" allele presented a higher frequency in controls than in cases $(0.920 \%$ vs. $0.83 \%)$ consequently; it was considered as a protective allele against cervical cancer among Tunisian women.

Since haplotype analysis of the ELAVL1 gene may further define the role of this gene in cervical cancer disease, haplotype analysis including all seven analyzed SNPs was performed between all the case patients and the control subjects.

We computed the linkage disequilibrium (LD) between nearby variants and it is described by $D^{\prime}$ and $r$ 2 (McKay, Schnabel et al. 2007, Bohmanova, Sargolzaei et al. 2010).

Figure 1 shows that the analyzed SNPs rs12983784, rs14394, rs74369359,

rs35986520,rs10402477,rs12985234 and rs2042920 together constitute a relatively weak LD block, and there was a significant linkage between rs35986520 and rs2042920 ( $\left.D^{\prime}=0.996, r 2=0.035\right)$ (Figure 2), Similarly between rs2042920 and rs10402477 $\left(D^{\prime}=0.998, r 2=0.026\right)$ (Figure 3$)$, indicating a strong $L D$ between these markers, with a weak linkage between rs14394 and rs2042920 ( $\left.D^{\prime}=0.698\right)$ (Table 5). 
The association analysis results between haplotypes and cervical cancer risk are shown in Table 6 . The haplotype "C C G G C A G" ( $P=0.02)$, "T T G G T A T" ( $P=0.01)$ and "T T T G C A T" ( $P=0.002)$ were more prevalent among cases $(0.045 \%, 0.055 \%$ and $0.040 \%$ respectively) than among controls $(0.011 \%, 0.015 \%$ and $0 \%$, respectively) and were found to be significantly associated with an increased risk of cervical cancer. Also, "TCGACAT" $(P=0.04)$ and "TTGGCAT" $(P=0.04)$ were more prevalent haplotypes among controls $(0.032 \%$ and $0.494 \%$, respectively) than among cases ( $0 \%$ and $0.336 \%$, respectively), suggesting a protective effect against cervical cancer susceptibility.

The haplotype analysis of rs35986520 and rs2042920 SNPs in the cervical cancer group and controls showed that the frequencies of AT, GG and GT were not statistically significant $(P>0.05)$ (Table 7). As a result, no correlation was found between this haplotype and cervical cancer among Tunisian women.

We performed an haplotype analysis of rs10402477 and rs2042920 SNPs. The haplotype TT

$(P=0.0001)$ presented a significant association with cervical cancer susceptibility. The haplotype TT frequency was significantly more enriched in patients with cervical cancer than in controls $(O R=6.022$, $95 \% \mathrm{Cl}=2.192 \sim 16.545)$. Furthermore, there was a statistically significant global effect of the haplotype $(P=0.0005)$ (Table 8).

\section{Discussion}

In this study, we observed that the risk of developing cervical cancer was higher among women who had given birth to five or more children. During pregnancy, women are more sexually active and therefore more exposed to HPV, which is a major cause of the main types of cervical cancer. Also pregnant women are more vulnerable to cancer because of the hormonal changes and the immune system modulation (Shah, Imami et al. 2018, Jørgensen, Persson et al. 2019).

Furthermore, menopausal status may also be a potential factor. Post-menopausal women were at higher risk than those who were not yet at menopause. This is in agreement with other research papers; a study done by Gyllensten et al. has shown that post-menopausal women are at a higher risk of contracting HPV virus (Gyllensten, Gustavsson et al. 2012). Another similar study carried out by Singh B and Nalini N. estimates the incidence of cervical cancer in post-menopausal women at 16\% (Singh and Nalini 2017).

There is growing evidence that Tunisian women who experience menarche before the age of 16 may have an increased risk for cervical cancer. Several studies have supported this finding and suggested that anovulatory cycles are common in the first years after menarche, which is associated with a decreased production of progesterone that leads to a decreased production of cervical mucus. That mucus acts as a barrier to sexually transmitted infections including HPV infection (Syrjänen, Shabalova et al. 2008).

Another theory also supported the probability of a higher risk of cervical cancer in women exposed to HPV infection immediately after menarche including greater areas of ectopy, a very active maturation 
process (active metaplasia), and higher affinity of high-risk HPV types with changes in the local immune response of an immature cervix. . The immature cervix is more vulnerable to HPV infection (Toon, Arrand et al. 1986, Castle, Jeronimo et al. 2006).

Having relatives with any type of cancer puts patients at a higher risk than healthy control women with no family history of the disease. We cannot be sure whether this is linked to genes, or whether it is due to common shared family habits like diet, healthcare, daily routine, socio-economic status or exposure to environmental risk factors.

The increased incidence of cervical cancer in the Tunisian population shows an urgent need to identify multiple genetic lesions leading to aberrant gene expression programs that are responsible for the cancer phenotype.

Recently, several studies have investigated genes coding for proteins, which regulate a variety of biological processes like cell growth, proliferation, apoptosis, and metabolic pathways that could be potentially useful in cancer diagnosis, prognosis, and therapy (Terasaka, Kim et al. 2019, Xie, Wang et al. 2021).

From this point of view, the study of polymorphisms in genes involved in carcinogenic mechanisms is promising, especially genes coding for RNA-binding proteins (RBPs). One such RBP is ELAVL1 also known as HuR (Szabo, Dalmau et al. 1991). Additionally, ELAVL1 binds almost exclusively to cellular mRNAs and more specifically at introns and 3'UTRs (Chen and Shyu 1995, Bakheet, Hitti et al. 2018).

The RBP Elavl1/HuR is believed to have ubiquitous expression patterns in most tissues (Ma, Cheng et al. 1996, Lu and Schneider 2004) and has three distinct and highly conserved RNA-binding domains belonging to the RNA-recognition motif (RRM) family (Wächter, Köhn et al. 2013). ELAVL1 has been shown to be primarily localized at the nucleus but can translocate to the cytoplasm via phosphorylation of Y200, S202, and S221, located in the hinge region of the protein between the second and third RRM (Chen and Shyu 1995).

Furthermore, HuR could contribute to the aberrant gene overexpression and promotes the tumorigenesis, by binding selectively to poly-U elements and AU-rich elements (AREs) in the 3'-UTR of target mRNAs for post-transcriptional regulation (Bakheet, Hitti et al. 2018).

The ELAVL1 gene located in chromosome 19p13.2 (Ma and Furneaux 1997) has been implicated in the occurrence and development of various human cancers. Although, abundant literature has highlighted its oncogenic effects (López de Silanes, Lal et al. 2005, Li, Huang et al. 2020, Ni, He et al. 2020, PalomoIrigoyen, Pérez-Andrés et al. 2020).

Fang Xue's study indicated that miRNA-139-3p inhibited the progression of ovarian cancer cells via inhibiting the expression of ELAVL1 (Xue, Li et al. 2019). 
A previous study of Ming-Jun Fan and his colleagues observed that ELAVL1 was upregulated in cervical cancer cells and was reported to promote cancer cell growth through regulating RNA in the cell cytoplasm (Fan, He et al. 2020).

The present study investigated a possible association between the ELAVL1 gene SNPs and the risk of cervical cancer among Tunisian women.

The investigated SNPs were genotyped according to the difference in melting curves established by HRM. This method of post-PCR is used for identifying genetic variants in suitable regions of interest in our candidate gene.

As a result of this case-control study, no association was found between the ELAVL1 gene SNPs (rs14394, rs35986520, rs1298524 and rs2042920) and the risk of developing cervical cancer. Conversely, women carrying ELAVL1 gene SNPs (rs12983784, rs74369359 and rs10402477) have a high risk for this disease.

Rohit Upadhyay's report indicated that according to db SNP (https://www.ncbi.nlm.nih.gov/snp/) the ELAVL1 gene has more than 400 SNPs, most of them have less than 5\% MAF (Minor allele frequency). By contrast, the selected SNPs had a MAF that is superior to $5 \%$ and therefore chosen for our study (Upadhyay, Sanduja et al. 2013).

A study of Rothamel and al. showed that 3'UTR binding confers enrichment and transcript stability and demonstrated that ELAVL1 mediates the RNA stability of genes that regulate pathways essential to pathogen sensing and cytokine production (Wanke, Devanna et al. 2018).

Multiple diseases arising from anomalies in this region affect the expression of one or more genes, especially cancer.

According to previous studies and to our findings, the possible explanation is that ELAVL1 single nucleotide polymorphisms in the $3^{\prime} \mathrm{UTR}$ region can be in the AU-rich region, which leads to dysregulation of ARE-binding proteins and cause tumorigenesis. Thus, women with ELAVL1 gene SNPs rs12983784, rs74369359 and rs10402477, which are, located in the 3'UTR region, presented high risqué of cervical cancer disease.

In this study, we assessed the association between rs35986520 and rs2042920 SNPs and between rs2042920 and rs10402477 SNPs, using a haplotype-based case-control analysis. The rs 10402477 was significantly different between cervical cancer patients and control participants, indicating that the risk of this cancer is increased among women with the T allele of rs10402477 and women with the $C$ allele of the SNP rs12983784. A study of Morris and Kaplan indicated that when linkage disequilibria between SNPs, multiple susceptibility alleles, is weak, an analysis based on haplotypes has advantages over analysis based on individual SNPs (Morris and Kaplan 2002). Consequently, we established haplotypes for the ELAVL1 gene from the different combinations of the seven SNPs. The frequencies of the "C C G G C A G", "T T G G T A T" and "T T T G C A T" were associated with a significant increased risk for cervical 
cancer. However, the "TCGACAT" and the "TTGGCAT" frequencies were associated with a decreased risk for cervical cancer.

rs2042920, which was in strong LD with rs10402477, was reported to be associated with increased cervical cancer risk in the Tunisian population. Although this study suggested that rs 2042920 had no impact on cervical cancer risk in Tunisian women, only its association with the rs10402477 SNP can lead to a rise in cancer risk. As rs 10402477 SNP was uniquely higher in patients compared with control subjects, it is obvious that this SNP is a genetic risk factor for cervical cancer among Tunisian women.

The same results were obtained for rs35986520, which was in strong LD with rs2042920; no significant association was seen with cervical cancer in Tunisian participants.

A possible explanation for the observed results is a possible functional combination of SNP alleles that could alter the ELAVL1 function. The presence of several simultaneous SNPs could alter more the interaction between ELAVL1 and AREs.

In summary, the current study detected the genotypes of patients with cervical cancer and healthy controls in a Tunisian population using the HRM. A significant association was observed between the ELAVL1 gene SNPs (rs12983784, rs74369359 and rs10402477) and the risk of cervical cancer. Also, Haplotype consisting of the two SNPs rs2042920 and rs10402477 strengthened the association with this cancer susceptibility. This finding provides evidence that ELAVL1 gene SNPs may be applied as a promising marker of genetic susceptibility to cervical cancer in Tunisian population.

Additional studies can confirm our results of genetic variation in ELAVL1 as a novel prognostic marker and therapeutic target of cervical cancer.

Nevertheless, the low sample size is a limitation of our study. Therefore, enlarging our sample size and providing more clinical analysis should be considered in the future to confirm this study finding.

\section{Abbreviations}

HPV: human papillomavirus

SNP: single nucleotide polymorphism

HRM: High resolution melting

OR: odds ratio

ARE: adenylate and uridylate (AU)-rich elements

HuR: Hu antigen R; ELAV Like1

ELAVL1: Embryonic Lethal, Abnormal Vision, Drosophila)-Like 1 (Hu Antigen R) 
RRM: RNA recognition motifs

3'-UTR: three prime untranslated region

\section{Declarations}

\section{Acknowledgements}

The authors are grateful to all assistants in the Department of Gynecology Obstetric, Tahar Sfar University Hospital, 5111 Mahdia, Tunisia, for their diligence and consistency in sample collection.

\section{Author's Contribution}

Conceptualization, Abderraouf KENANI and Najet Boudhiba; Data curation, Najet Boudhiba and Ahlem Helaoui ; Investigation, Najet Boudhiba and Ahlem Helaoui ; Methodology, Najet Boudhiba, Marcin Hołysz, Ewa Iwańczyk-Skalska and Sana Sfar; Project administration, Abderraouf KENANI and Paweł P. Jagodziński; Diagnostic of patients and controls, Najet Boudhiba and Haifa Bouchahda ; Supervision, Abderraouf KENANI; Validation, Abderraouf KENANI and Paweł P. Jagodziński; Visualization, Najet Boudhiba, Ewa Iwańczyk-Skalska and Marcin Hołysz ; Writing - original draft, Najet Boudhiba; Writing review \& editing, Najet Boudhiba and Abderraouf KENANI.

All authors read and approved the final manuscript.

\section{Compliance with ethical standards}

\section{Funding}

This research did not receive any specific grant from funding agencies in the public, commercial, or notfor-profit sectors.

\section{Conflicts of Interest/competing interests}

The authors declare that the research was conducted in the absence of any commercial or financial relationships that could be construed as a potential conflict of interest.

\section{Ethical approval}

Approval of the ethical standards of the Ethics Committee for Research in Life Sciences and Health of the ISBM (CER-SVS/ISBM 007/2021) was obtained. 


\section{Consent to participate}

Informed written consent was obtained from all women according to the ethical standards of the Ethics Committee for Research in Life Sciences and Health of the ISBM (CER-SVS/ISBM).

\section{Consent for publication}

Informed consent was obtained from all participants for whom identifying information is included in this article.

\section{Availability of data and material}

Not applicable

\section{Code availability}

Not applicable

\section{References}

1. Asthana, S., V. Busa and S. Labani (2020). "Oral contraceptives use and risk of cervical cancer-A systematic review \& meta-analysis." Eur J Obstet Gynecol Reprod Biol 247: 163-175.

2. Bahrami, A., M. Hasanzadeh, S. Shahidsales, M. Farazestanian, S. M. Hassanian, M. Moetamani Ahmadi, M. Maftouh, M. Gharib, Z. Yousefi, S. Kadkhodayan, G. A. Ferns and A. Avan (2018). "Genetic susceptibility in cervical cancer: From bench to bedside." J Cell Physiol 233(3): 1929-1939.

3. Bakheet, T., E. Hitti, M. Al-Saif, W. N. Moghrabi and K. S. A. Khabar (2018). "The AU-rich element landscape across human transcriptome reveals a large proportion in introns and regulation by ELAVL1/HuR." Biochim Biophys Acta Gene Regul Mech 1861(2): 167-177.

4. Bohmanova, J., M. Sargolzaei and F. S. Schenkel (2010). "Characteristics of linkage disequilibrium in North American Holsteins." BMC Genomics 11: 421.

5. Castle, P. E., J. Jeronimo, M. Schiffman, R. Herrero, A. C. Rodríguez, M. C. Bratti, A. Hildesheim, S. Wacholder, L. R. Long, L. Neve, R. Pfeiffer and R. D. Burk (2006). "Age-related changes of the cervix influence human papillomavirus type distribution." Cancer Res 66(2): 1218-1224.

6. Charbotel, B., A. Massardier-Pilonchery, E. Fort, B. Dananché, J. Févotte, C. Confavreux-Romestaing and A. Bergeret (2013). "Occupational trichloroethylene exposure and cervical pathology: a casecontrol study." Ann Occup Hy.g 57(3): 407-416.

7. Chen, C. Y. and A. B. Shyu (1995). "AU-rich elements: characterization and importance in mRNA degradation." Trends Biochem Sci 20(11): 465-470. 
8. Chen, T., S. Yang, J. Xu, W. Lu and X. Xie (2020). "Transcriptome sequencing profiles of cervical cancer tissues and SiHa cells." Funct Integr Genomics 20(2): 211-221.

9. Fan, M. J., P. J. He, X. Y. Lin, C. R. Yang, C. Z. Li and L. G. Xing (2020). "MicroRNA-324-5p affects the radiotherapy response of cervical cancer via targeting ELAV-like RNA binding protein 1." Kaohsiung $\_$ Med Sci 36(12): 965-972.

10. Fang, C. Y., M. Lee, Z. Feng, Y. Tan, F. Levine, C. Nguyen and G. X. Ma (2019). "Community-Based Cervical Cancer Education: Changes in Knowledge and Beliefs Among Vietnamese American Women." J Community Health 44(3): 525-533.

11. Filippova, N. and L. B. Nabors (2020). "ELAVL1 Role in Cell Fusion and Tunneling Membrane Nanotube Formations with Implication to Treat Glioma Heterogeneity." Cancers (Basel). 12(10).

12. Gyllensten, U., I. Gustavsson, M. Lindell and E. Wilander (2012). "Primary high-risk HPV screening for cervical cancer in post-menopausal women." Gynecol Oncol 125(2): 343-345.

13. Jørgensen, N., G. Persson and T. V. F. Hviid (2019). "The Tolerogenic Function of Regulatory T Cells in Pregnancy and Cancer." Front Immunol 10: 911.

14. Kashyap, N., N. Krishnan, S. Kaur and S. Ghai (2019). "Risk Factors of Cervical Cancer: A CaseControl Study." Asia Pac J Oncol Nurs 6(3): 308-314.

15. Li, K., F. Huang, Y. Li, D. Li, H. Lin, R. Ni, Q. Zhang, M. Zhao, S. Huang, L. Zou and C. Huang (2020). "Stabilization of oncogenic transcripts by the IGF2BP3/ELAVL1 complex promotes tumorigenicity in colorectal cancer." Am J Cancer Res 10(8): 2480-2494.

16. Lim, S. J., H. J. Kim, J. Y. Kim, K. Park and C. M. Lee (2007). "Expression of HuR is associated with increased cyclooxygenase-2 expression in uterine cervical carcinoma." Int J Gynecol Pathol 26(3): 229-234.

17. López de Silanes, I., A. Lal and M. Gorospe (2005). "HuR: post-transcriptional paths to malignancy." RNA Biol 2(1): 11-13.

18. Lu, J. Y. and R. J. Schneider (2004). "Tissue distribution of AU-rich mRNA-binding proteins involved in regulation of mRNA decay." J Biol Chem 279(13): 12974-12979.

19. Ma, W. J., S. Cheng, C. Campbell, A. Wright and H. Furneaux (1996). "Cloning and characterization of HuR, a ubiquitously expressed Elav-like protein." J Biol Chem 271(14): 8144-8151.

20. Ma, W. J. and H. Furneaux (1997). "Localization of the human HuR gene to chromosome 19p13.2." Hum Genet 99(1): 32-33.

21. McKay, S. D., R. D. Schnabel, B. M. Murdoch, L. K. Matukumalli, J. Aerts, W. Coppieters, D. Crews, E. Dias Neto, C. A. Gill, C. Gao, H. Mannen, P. Stothard, Z. Wang, C. P. Van Tassell, J. L. Williams, J. F. Taylor and S. S. Moore (2007). "Whole genome linkage disequilibrium maps in cattle." BMC Genet 8 : 74.

22. Medina-Contreras, O., J. Luvián-Morales, F. Valdez-Palomares, L. Flores-Cisneros, M. S. SánchezLópez, J. H. Soto-Lugo and D. Castro-Eguiluz (2020). "IMMUNONUTRITION IN CERVICAL CANCER: IMMUNE RESPONSE MODULATION BY DIET." Rev Invest Clin 72(4): 219-230. 
23. Morris, R. W. and N. L. Kaplan (2002). "On the advantage of haplotype analysis in the presence of multiple disease susceptibility alleles." Genet Epidemiol 23(3): 221-233.

24. Ni, Z. Z., J. K. He, X. Tang, Z. Tao, Y. Zhang and B. Xie (2020). "Identification of ELAVL1 gene and miRNA-139-3p involved in the aggressiveness of NSCLC." Eur Rev Med Pharmacol Sci 24(18): 94539464.

25. Palomo-Irigoyen, M., E. Pérez-Andrés, M. Iruarrizaga-Lejarreta, A. Barreira-Manrique, M. Tamayo-Caro, L. Vila-Vecilla, L. Moreno-Cugnon, N. Beitia, D. Medrano, D. Fernández-Ramos, J. J. Lozano, S. Okawa, J. L. Lavín, N. Martín-Martín, J. D. Sutherland, V. G. de Juan, M. Gonzalez-Lopez, N. Macías-Cámara, D. Mosén-Ansorena, L. Laraba, C. O. Hanemann, E. Ercolano, D. B. Parkinson, C. W. Schultz, M. J. Araúzo-Bravo, A. M. Ascensión, D. Gerovska, H. Iribar, A. Izeta, P. Pytel, P. Krastel, A. Provenzani, P. Seneci, R. D. Carrasco, A. Del Sol, M. L. Martinez-Chantar, R. Barrio, E. Serra, C. Lazaro, A. M. Flanagan, M. Gorospe, N. Ratner, A. M. Aransay, A. Carracedo, M. Varela-Rey and A. Woodhoo (2020). "HuR/ELAVL1 drives malignant peripheral nerve sheath tumor growth and metastasis." $\underline{\mathrm{J} \text { Clin Invest }}$ 130(7): 3848-3864.

26. Pauzas, H., U. Gyvyte, T. Latkauskas, L. Kairevice, P. Lizdenis, S. Svagzdys, E. Birgiolaite, I. Kuliaviene, J. Kupcinskas and A. Tamelis (2020). "The Role of VEGFA, COX2, HUR and CUGBP2 in Predicting the Response to Neoadjuvant Therapy in Rectal Cancer Patients." Medicina (Kaunas). 56(4).

27. Rothamel, K., S. Arcos, B. Kim, C. Reasoner, S. Lisy, N. Mukherjee and M. Ascano (2021). "ELAVL1 primarily couples mRNA stability with the 3' UTRs of interferon-stimulated genes." Cell Rep 35(8): 109178.

28. Shah, N. M., N. Imami and M. R. Johnson (2018). "Progesterone Modulation of Pregnancy-Related Immune Responses." Front Immunol 9: 1293.

29. Singh, B. and N. Nalini (2017). "Study of incidence and different aspects of cervical malignancy in tertiary centre of Jharkhand, India." International Journal of Reproduction, Contraception, Obstetrics and Gynecology 6: 3118.

30. Spence, A. R., E. L. Franco and A. Ferenczy (2005). "The Role of Human Papillomaviruses in Cancer." American Journal of Cancer 4(1): 49-64.

31. Sugawara, Y., I. Tsuji, T. Mizoue, M. Inoue, N. Sawada, K. Matsuo, H. Ito, M. Naito, C. Nagata, Y. Kitamura, A. Sadakane, K. Tanaka, A. Tamakoshi, S. Tsugane and T. Shimazu (2019). "Cigarette smoking and cervical cancer risk: an evaluation based on a systematic review and meta-analysis among Japanese women." Jpn J Clin Oncol 49(1): 77-86.

32. Sung, H., J. Ferlay, R. L. Siegel, M. Laversanne, I. Soerjomataram, A. Jemal and F. Bray (2021). "Global Cancer Statistics 2020: GLOBOCAN Estimates of Incidence and Mortality Worldwide for 36 Cancers in 185 Countries." CA Cancer J Clin 71(3): 209-249.

33. Syrjänen, K., I. Shabalova, N. Petrovichev, V. Kozachenko, T. Zakharova, J. Pajanidi, J. Podistov, G. Chemeris, L. Sozaeva, E. Lipova, I. Tsidaeva, O. Ivanchenko, A. Pshepurko, S. Zakharenko, R. Nerovjna, L. Kljukina, O. Erokhina, M. Branovskaja, M. Nikitina, V. Grunberga, A. Grunberg, A. Juschenko, R. Santopietro, M. Cintorino, P. Tosi and S. Syrjänen (2008). "Age at menarche is not an 
independent risk factor for high-risk human papillomavirus infections and cervical intraepithelial neoplasia." Int J STD AIDS 19(1): 16-25.

34. Szabo, A., J. Dalmau, G. Manley, M. Rosenfeld, E. Wong, J. Henson, J. B. Posner and H. M. Furneaux (1991). "HuD, a paraneoplastic encephalomyelitis antigen, contains RNA-binding domains and is homologous to Elav and Sex-lethal." Cell 67(2): 325-333.

35. Tang, Q., Z. Chen, L. Zhao and H. Xu (2019). "Circular RNA hsa_circ_0000515 acts as a miR-326 sponge to promote cervical cancer progression through up-regulation of ELK1." Aging_(Albany NY). 11(22): 9982-9999.

36. Terasaka, T., T. Kim, H. Dave, B. Gangapurkar, D. A. Nicholas, O. Muñoz, E. Terasaka, D. Li and M. A. Lawson (2019). "The RNA-Binding Protein ELAVL1 Regulates GnRH Receptor Expression and the Response to GnRH." Endocrinology_ 160(8): 1999-2014.

37. Tifaoui, N., T. Maudelonde, J. Combecal, R. Vallo, S. Doutre, M. N. Didelot, N. Nagot, M. Segondy and N. Boulle (2018). "High-risk HPV detection and associated cervical lesions in a population of French menopausal women." J Clin Virol 108: 12-18.

38. Toon, P. G., J. R. Arrand, L. P. Wilson and D. S. Sharp (1986). "Human papillomavirus infection of the uterine cervix of women without cytological signs of neoplasia." Br Med J (Clin Res Ed). 293(6557): 1261-1264.

39. Upadhyay, R., S. Sanduja, V. Kaza and D. A. Dixon (2013). "Genetic polymorphisms in RNA binding proteins contribute to breast cancer survival." Int J Cancer 132(3): E128-138.

40. Wächter, K., M. Köhn, N. Stöhr and S. Hüttelmaier (2013). "Subcellular localization and RNP formation of IGF2BPs (IGF2 mRNA-binding proteins) is modulated by distinct RNA-binding domains." Biol Chem 394(8): 1077-1090.

41. Walboomers, J. M., M. V. Jacobs, M. M. Manos, F. X. Bosch, J. A. Kummer, K. V. Shah, P. J. Snijders, J. Peto, C. J. Meijer and N. Muñoz (1999). "Human papillomavirus is a necessary cause of invasive cervical cancer worldwide." J Pathol 189(1): 12-19.

42. Wang, J., Y. Guo, H. Chu, Y. Guan, J. Bi and B. Wang (2013). "Multiple functions of the RNA-binding protein HuR in cancer progression, treatment responses and prognosis." Int J Mol Sci 14(5): 1001510041.

43. Wanke, K. A., P. Devanna and S. C. Vernes (2018). "Understanding Neurodevelopmental Disorders: The Promise of Regulatory Variation in the 3'UTRome." Biol Psychiatry 83(7): 548-557.

44. Xie, W., Y. Wang, Y. Zhang, Y. Xiang, N. Wu, L. Wu, C. Li, T. Cai, X. Ma, Z. Yu, L. Bai and Y. Li (2021). "Single-nucleotide polymorphism rs4142441 and MYC co-modulated long non-coding RNA OSER1AS1 suppresses non-small cell lung cancer by sequestering ELAVL1." Cancer Sci 112(6): 2272-2286.

45. Xue, F., Q. R. Li, Y. H. Xu and H. B. Zhou (2019). "MicroRNA-139-3p Inhibits The Growth And Metastasis Of Ovarian Cancer By Inhibiting ELAVL1." Onco Targets Ther 12: 8935-8945.

46. Yang, L. Q., S. P. Yu, Y. T. Yang, Y. S. Zhao, F. Y. Wang, Y. Chen, Q. H. Li, P. Tian, Y. Y. Zhu, J. G. Zhang and G. Q. Lin (2021). "Muscone derivative ZM-32 inhibits breast tumor angiogenesis by suppressing HuR-mediated VEGF and MMP9 expression." Biomed Pharmacother 136: 111265. 


\section{Tables}

Table 1

Details of genotyped SNPs in ELAVL1 gene

\begin{tabular}{|c|c|c|c|c|c|}
\hline Gene/SNP & $\begin{array}{l}\text { SNP rs } \\
\text { number }\end{array}$ & $\begin{array}{l}\text { Nucleotide } \\
\text { change }\end{array}$ & $\begin{array}{l}\text { SNP } \\
\text { location }\end{array}$ & Primer sequences & $\begin{array}{l}\text { Product } \\
\text { size }\end{array}$ \\
\hline \multirow[t]{2}{*}{ ELAVL1 } & \multirow[t]{2}{*}{ rs12983784 } & \multirow[t]{2}{*}{$\mathrm{T}>\mathrm{C}$} & \multirow[t]{2}{*}{ 3'UTR } & F:ACACTGAAAACGAAATAATGGC & \multirow[t]{2}{*}{$121 \mathrm{bp}$} \\
\hline & & & & R:TTGACCCGTGTGTAACTTCC & \\
\hline \multirow[t]{2}{*}{ ELAVL1 } & \multirow[t]{2}{*}{ rs14394 } & \multirow[t]{2}{*}{$\mathrm{T}>\mathrm{C}$} & \multirow{2}{*}{$\begin{array}{l}\text { Coding } \\
\text { region }\end{array}$} & F:GCGGATCACTTTCACATTGG & \multirow[t]{2}{*}{94 bp } \\
\hline & & & & R:TTTCATCTACAACCTGGGGC & \\
\hline \multirow[t]{2}{*}{ ELAVL1 } & \multirow[t]{2}{*}{ rs74369359 } & \multirow[t]{2}{*}{$G>T$} & \multirow[t]{2}{*}{ 3'UTR } & F:TTATCGTGAACAACAGTATCC & \multirow[t]{2}{*}{ 132bp } \\
\hline & & & & R:TCCAGTATATTCCAGAGTCAG & \\
\hline \multirow[t]{2}{*}{ ELAVL1 } & \multirow[t]{2}{*}{ rs35986520 } & \multirow[t]{2}{*}{$G>A$} & \multirow[t]{2}{*}{ 3'UTR } & F:AAGGCTTCTTTTTCCAGGA & \multirow[t]{2}{*}{72 bp } \\
\hline & & & & R:GGGTCCCTGCTCTGTTG & \\
\hline \multirow[t]{2}{*}{ ELAVL1 } & \multirow[t]{2}{*}{ rs10402477 } & \multirow[t]{2}{*}{$C>T$} & \multirow[t]{2}{*}{ 3'UTR } & F:GAGCAGGGACCCTCTTTT & \multirow[t]{2}{*}{$82 \mathrm{bp}$} \\
\hline & & & & R:CTCCCACAGAATCCCAGA & \\
\hline \multirow[t]{2}{*}{ ELAVL1 } & \multirow[t]{2}{*}{ rs12985234 } & \multirow[t]{2}{*}{$A>G$} & \multirow[t]{2}{*}{ 3'UTR } & F:GCCGACTTTTATGAGACAC & \multirow[t]{2}{*}{$95 \mathrm{bp}$} \\
\hline & & & & R:CTTTCCCTGATCTTTTACTG & \\
\hline \multirow[t]{2}{*}{ ELAVL1 } & \multirow[t]{2}{*}{ rs2042920 } & \multirow[t]{2}{*}{$T>G$} & \multirow[t]{2}{*}{ 3'UTR } & F:TTGCGAAGTTTGGGGACAG & \multirow[t]{2}{*}{103 bp } \\
\hline & & & & R:CAGACCTACCTCACСТАCT & \\
\hline
\end{tabular}


Table 2

Clinical and demographic characteristics of the patients and controls

\begin{tabular}{|c|c|c|c|c|}
\hline Characteristics & $\begin{array}{c}\text { Controls }(n=100) \\
(n \%)\end{array}$ & $\begin{array}{c}\text { Cases }(n=71) \\
(n \%)\end{array}$ & P-value & $\begin{array}{l}\text { Odd ratio } \\
(95 \% \text { CI) }\end{array}$ \\
\hline \multicolumn{5}{|l|}{ Age } \\
\hline$<18$ & $2(2)$ & $1(1.4)$ & 0.15 & $2.4(0.76-7.57)$ \\
\hline $18 \leq$ Age $\leq 50$ & $69(69)$ & $50(70.4)$ & 0.13 & $1.01(0.51-1.95)$ \\
\hline $50<$ & $29(29)$ & $20(28.2)$ & 0.99 & - \\
\hline \multicolumn{5}{|l|}{ Number of } \\
\hline \multicolumn{5}{|c|}{ Pregnancies (NP) } \\
\hline$\leq 2$ & $36(36)$ & $17(23.9)$ & 0.04 & - \\
\hline $2<\mathrm{NP} \leq 5$ & $42(42)$ & $29(40.8)$ & 0.45 & $1.3(0.64-2.08)$ \\
\hline $5<$ & $22(22)$ & $25(25.2)$ & 0.02 & $2.4(1.1-5.51)$ \\
\hline \multicolumn{5}{|l|}{ Childbirth (CB) } \\
\hline$<2$ & $44(44)$ & $26(36.6)$ & 0.22 & - \\
\hline $2 \leq \mathrm{CB} \leq 5$ & $46(46)$ & $37(52.1)$ & 0.4 & $1.3(0.69-2.49)$ \\
\hline $5<$ & $10(10)$ & $8(11.13)$ & 0.08 & $2.18(0.9-5.27)$ \\
\hline \multirow{2}{*}{\multicolumn{5}{|c|}{$\begin{array}{l}\text { Use of oral } \\
\text { Contraceptive }\end{array}$}} \\
\hline & & & & \\
\hline No & $40(40)$ & $24(33.8)$ & 0.81 & - \\
\hline Yes & $60(60)$ & $47(66.2)$ & 0.81 & $1.07(0.58-1.95)$ \\
\hline \multicolumn{5}{|c|}{ Family history } \\
\hline \multicolumn{5}{|l|}{ Of cancer } \\
\hline No & $61(61)$ & $30(42.3)$ & 0.012 & - \\
\hline Yes & $39(39)$ & $41(57.7)$ & 0.012 & $2.18(1.18-4.02)$ \\
\hline \multicolumn{5}{|l|}{ Education } \\
\hline Illiterate & $27(27)$ & $19(26.8)$ & 0.03 & $1.55(0.75-3.2)$ \\
\hline Primary school & $22(22)$ & $26(36.6)$ & 0.23 & $2.58(1.24-5.26)$ \\
\hline High school & $51(51)$ & $26(36.6)$ & 0.01 & - \\
\hline \multicolumn{5}{|l|}{ Occupation } \\
\hline Unemployed & $62(62)$ & $53(74.6)$ & 0.4 & $1.29(0.71-2.35)$ \\
\hline Employed & $38(38)$ & $18(25.4)$ & 0.4 & - \\
\hline \multicolumn{5}{|c|}{ Marital Status } \\
\hline Single & $10(10)$ & $5(7)$ & 0.14 & $1.56(0.85-2.85)$ \\
\hline Married & $90(90)$ & $66(93)$ & 0.14 & - \\
\hline \multicolumn{5}{|c|}{ Age at menarche } \\
\hline$<16$ & $92(92)$ & $92(91.9)$ & 0.04 & - \\
\hline $16 \leq$ & $8(8)$ & $7(9.9)$ & 0.04 & $1.89(1.03-3.47)$ \\
\hline \multicolumn{5}{|l|}{ Menopausal } \\
\hline No & $66(66)$ & $39(54.9)$ & 0.04 & - \\
\hline Yes & $34(34)$ & $32(45.1)$ & 0.04 & $1.8(0.98-3.3)$ \\
\hline
\end{tabular}


Table 3

Results of the ELAVL1 gene polymorphisms genotype by Group

\begin{tabular}{|c|c|c|c|c|}
\hline $\begin{array}{l}\text { SNPs/ } \\
\text { Genotypes }\end{array}$ & $\begin{array}{c}\text { Controls, } n=100 \\
(\%)\end{array}$ & $\begin{array}{c}\text { Cases, } n=71 \\
(\%)\end{array}$ & P-value & $\begin{array}{c}\text { Odd ratio (OR) } \\
(95 \%)\end{array}$ \\
\hline \multicolumn{5}{|l|}{ rs 12983784} \\
\hline TT & $\begin{array}{l}88(88) \\
8(8)\end{array}$ & $52(73.2)$ & $\begin{array}{l}0.005 \\
0.017\end{array}$ & $278(12-645)$ \\
\hline $\mathrm{TC}$ & $8(8)$ & 14 (19.7) & 0.017 & $2.78(1.2-6.45)$ \\
\hline $\begin{array}{l}\text { CC } \\
r s 14394\end{array}$ & $4(4)$ & $5(7.1)$ & 0.2 & $1.8(0.72-4.51)$ \\
\hline TT & $49(49)$ & $33(46.5)$ & 0.56 & - \\
\hline TC & 37 (37) & $29(40.8)$ & 0.55 & $1.2(0.63-4.3)$ \\
\hline $\mathrm{CC}$ & $14(14)$ & $9(12.7)$ & 0.29 & $1.53(0.68-3.4)$ \\
\hline \multicolumn{5}{|l|}{ rs74369359 } \\
\hline GG & $98(98)$ & $56(78.9)$ & 0.000 & - \\
\hline GT & $1(1)$ & $11(15.5)$ & 0.004 & $9.4(1.73-16.96)$ \\
\hline \multicolumn{4}{|l|}{ rs35986520 } & $1.17(0.36-3.84)$ \\
\hline GG & $85(85)$ & $57(80.3)$ & 0.08 & - \\
\hline GA & $13(13)$ & $13(18.3)$ & 0.24 & $1.62(0.72-3.68)$ \\
\hline \multicolumn{4}{|l|}{ rs 10402477} & $1.9(0.73-5.02)$ \\
\hline $\mathrm{CC}$ & $97(97)$ & $56(78.9)$ & 0.000 & - \\
\hline CT & $1(1)$ & $11(15.5)$ & 0.002 & $5.89(1.89-18.36)$ \\
\hline $\begin{array}{l}\text { TT } \\
\text { rs } 1298524\end{array}$ & $2(2)$ & $4(5.6)$ & 0.96 & $1.03(0.32-3.3)$ \\
\hline $\mathrm{AA}$ & $72(72)$ & $46(64.8)$ & 0.10 & - \\
\hline $\mathrm{AG}$ & $18(18)$ & $17(32.9)$ & 0.13 & $1.72(0.84-9.52)$ \\
\hline $\begin{array}{l}\text { GG } \\
\text { rs2042920 }\end{array}$ & $10(10)$ & $8(11.3)$ & 0.14 & $1.8(0.81-3.9)$ \\
\hline TT & $54(54)$ & $42(59.2)$ & 0.25 & - \\
\hline TG & $38(38)$ & $23(32.4)$ & 0.75 & $0.83(0.43-1.58)$ \\
\hline GG & $8(8)$ & $6(8.5)$ & 0.15 & $1.83(0.8-4.2)$ \\
\hline
\end{tabular}

A-adenine, C-cytosine, G-guanine and T-thymidine 
Table 4

Allele frequency analysis of ELAVL1 SNPs

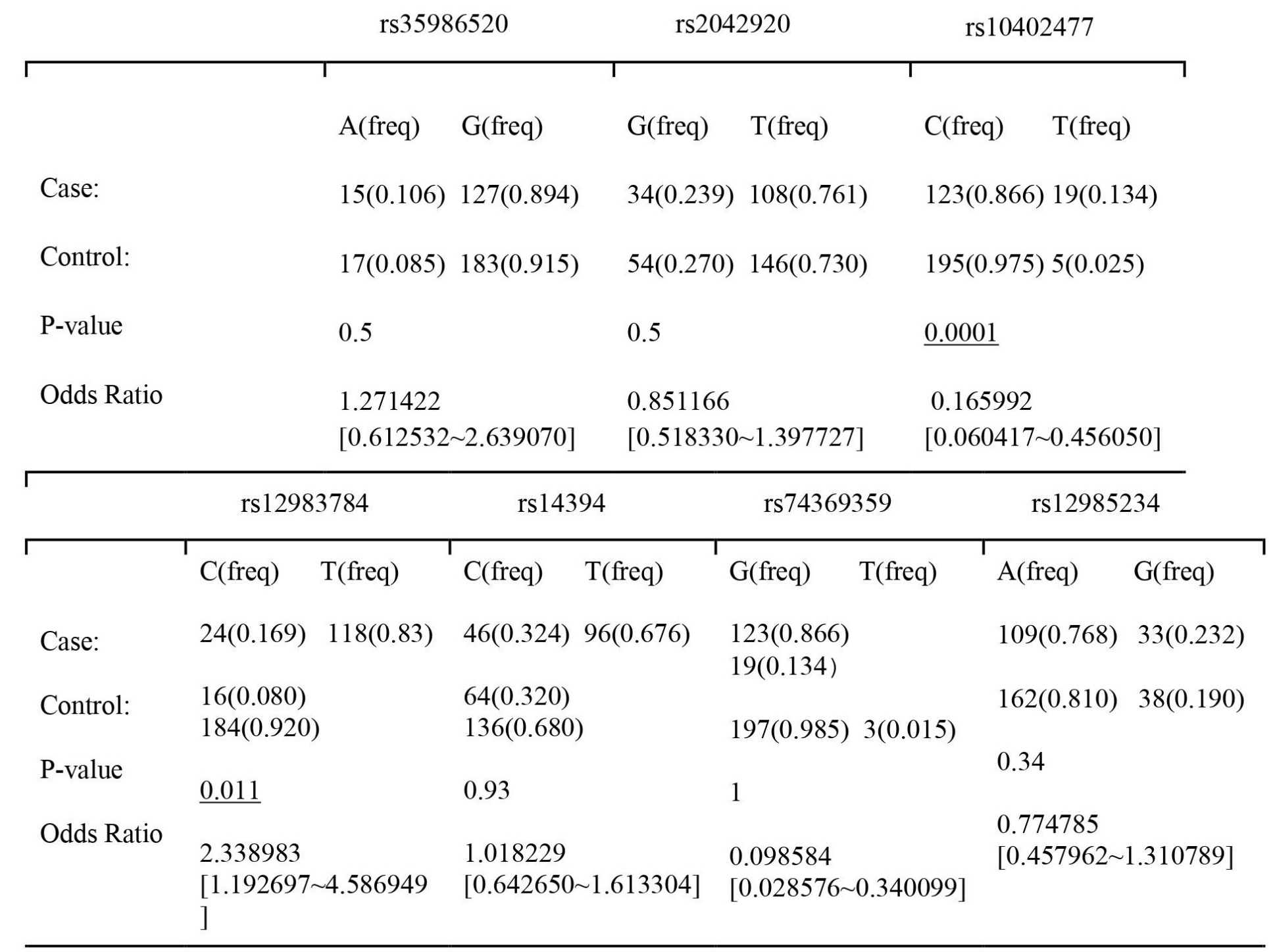

\section{Figures}




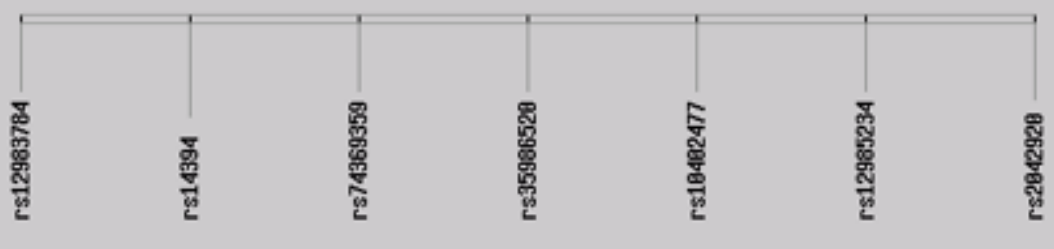

1

38
2

1

21
3

17

39

46
4

9
21

45

51
5

6

8

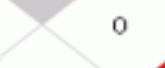

37

1

3

69

37

\section{Figure 1}

Analysis of linkage disequilibrium of the 7 SNPs; The color and figure were determined by the value of D'. Each colored cell is related to the strength of LD between the corresponding two markers. The number in each cell represents the LD parameter D' $(\times 100)$, an empty cell indicates $D^{\prime}(\times 100)=100$.

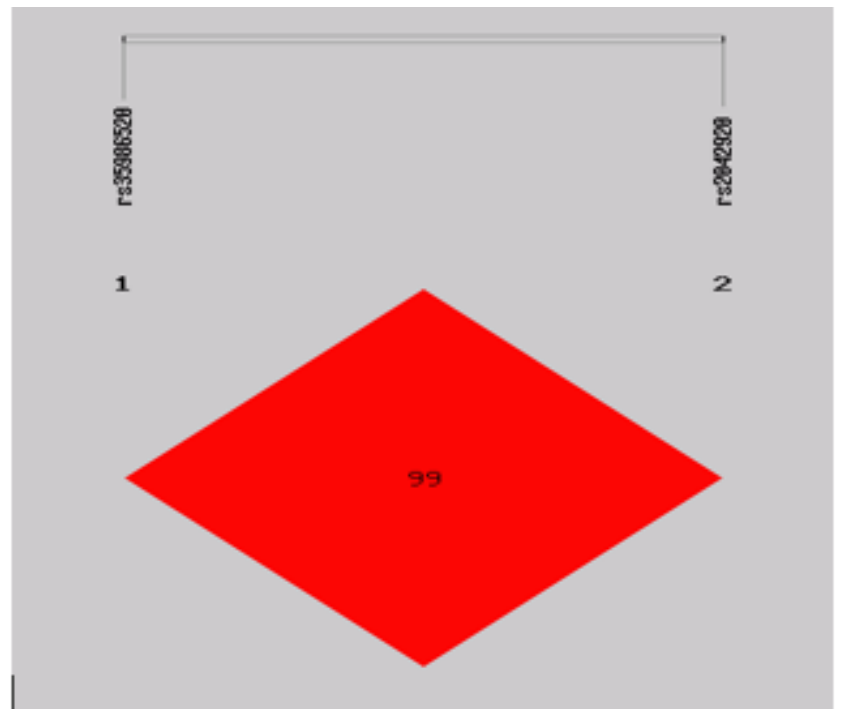

\section{Figure 2}

Linkage disequilibrium (LD) status of ELAVL1 rs2042920 and rs35986520 $D^{\prime}=0.996, r 2=0.035$ 


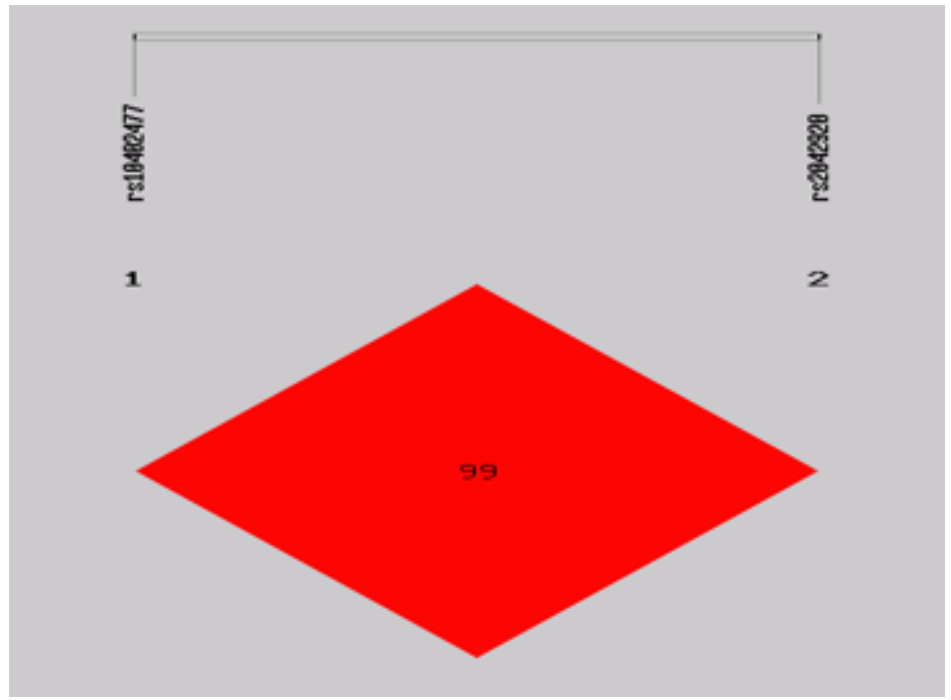

Figure 3

Linkage disequilibrium (LD) status of ELAVL1 rs2042920 and rs10402477 polymorphisms, $D^{\prime}=0.998, r 2=0.026$

\section{Supplementary Files}

This is a list of supplementary files associated with this preprint. Click to download.

- supplimentaryinformation.docx 